\title{
Краевые фотогальванические эффекты в двумерных кристаллах
}

\author{
С.А. Тарасенко \\ Физико-технический институт им. А.Ф. Иоффе, Санкт-Петербург, \\ 194021, Политехническая, 26 \\ mел:+7 (812) 247-2245, факс:+7 (812) 247-1017, эл.nочта: tarasenko@coherent.ioffe.ru
}

DOI 10.34077/RCSP2021-30

Миниатюризация приборов оптоэлектроники стимулирует поиск и исследование новых механизмов фотоэлектрического преобразования в микро- и наноструктурах, новых методов регистрации интенсивности и поляризации электромагнитного излучения.

В докладе представлены результаты теоретического и экспериментального исследования краевых фотогальванических эффектов в двумерных кристаллах. Продемонстрировано, что возбуждение двумерной структуры электромагнитным излучением приводит к генерации направленного электрического тока вдоль геометрической границы структуры; полярность тока зависит от поляризации излучения. Обсуждаются механизмы генерации краевого фототока для различных спектральных диапазонов, соответствующих как межзонным [1], так и внутризонным [2,3] оптическим переходам в структурах на основе графена и других двумерных дираковских материалах. Показана возможность многократного усиления фотоотклика в системах с латеральной сверхструктурой. Обсуждаются также эффекты генерации фототоков в киральных и спиральных краевых каналах двумерных топологических изоляторов $[4,5]$.

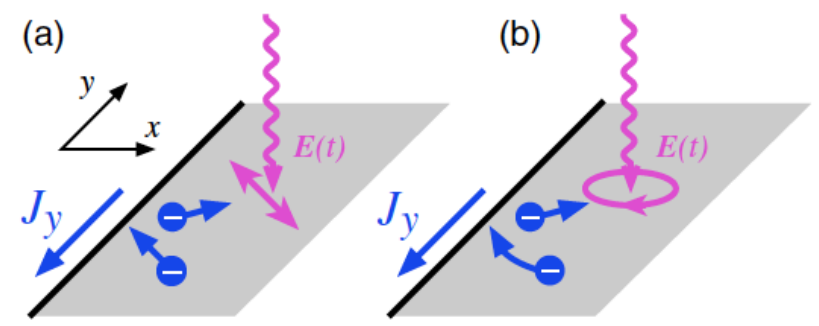

Рис. Возникновение краевого фототока при возбуждении двумерной структуры (a) линейно поляризованным и (b) циркулярно поляризованным излучением.
Краевой фотогальванический эффект связан с нарушением трансляционной симметрии кристалла, которое вносится краем. Эффект возникает при возбуждении структуры как линейно поляризованным, так и циркулярно поляризованным излучением. В спектральной области поглощения света свободными носителями заряда (механизм Друде) фототок содержит вклады, связанные с выстраиванием носителей заряда по импульсу и динамическим перераспределением заряда вблизи края. Фототок формируется в узкой полоске, которая определяется длиной

свободного пробега носителей заряда и длиной динамического экранирования электромагнитного поля. В спектральном диапазоне, соответствующем прямым оптическим переходам между валентной зоной и зоной проводимости, основной вклад в фототок обусловлен оптическим выстраиванием электронов и дырок по импульсу и последующим рассеянием носителей заряда на краю структуры.

Разработанная теория хорошо описывает зависимости фототока от поляризации излучения и магнитного поля, наблюдаемые на графеновых системах, и показывает, что краевой фотогальванический эффект может доминировать в фотоэлектрическом отклике микроструктур.

\section{Лuтература}

[1] M.V. Durnev and S.A. Tarasenko, Edge photogalvanic effect caused by optical alignment of carrier momenta in two-dimensional Dirac materials // Phys. Rev. B. 2021. V.103. P.165411.

[2] S. Candussio et al. Edge photocurrent driven by terahertz electric field in bilayer graphene // Phys. Rev. B. 2020. V.102. P.045406.

[3] M.V. Durnev and S.A. Tarasenko, Rectification of ac electric current at the edge of 2D electron gas // Phys. Status Solidi B. 2021. V. 258. P. 2000291.

[4] H. Plank et al., Edge currents driven by terahertz radiation in graphene in quantum Hall regime // 2D Materials. 2019. V.6. P.011002.

[5] M.V. Durnev and S.A. Tarasenko, High-frequency nonlinear transport and photogalvanic effects in 2D topological insulators // Ann. Phys. (Berlin). 2019. V.531. P.1800418. 